\section{Site-Directed Mutagenesis for Large Insertions by Oligonucleotide Primers in Optimized Molar Ratios}

BioTechniques 22:70-72 (January 1997)

Site-directed mutagenesis is a powerful tool to study gene expression and protein structure/function. There are numerous protocols to create deletion, insertion and substitution mutations of a DNA sequence of interest. The conventional method utilizes single-stranded (ss)DNA from M13-based vectors $(1,5,6,9)$ and an oligonucleotide primer containing the desired mutation. This method requires the production of ssDNA, which often entails subcloning of the DNA sequence of interest into special vectors. Polymerase chain reaction (PCR)-based mutagenesis procedures $(3,4,8)$ allow the quick creation of site-directed mutations; however, they either require the class IIs restriction enzymes or are subject to the difficulty of amplifying large plasmids with high efficiencies and the subsequent subcloning steps. The mutagenesis method described by Deng and Nickoloff (2) is a popular method to introduce specific base changes into virtually any doublestranded plasmid. This method relies on simultaneous annealing of two oligonucleotide primers to one strand of the target plasmid and DNA synthesis with T4 DNA polymerase, which does not possess strand-displacement activity. While one primer (mutagenic primer) introduces the desired mutation, the other one (selection primer) mutates a unique nonessential restriction site on the plasmid, thus allowing selection against the parental plasmid by restriction digestion. The efficiency to create single or multiple specific base changes and deletions are generally high, but insertion of a relatively large number of bases (>15 bp) is often associated with high background of plasmids, which do not contain the desired mutations. Insertion of a long DNA stretch requires the DNA-loop formation between the mutagenic primer and parental plasmid. Quite often, the problem of a high background is encountered by the generation of mutant plasmids that have re-

Table 1. Percentage of Desired Mutants from Simultaneous Annealing of Mutagenic and Selection Primers and Mutants from Annealing of Selection Primer Only With Various Molar Ratios and Quick or Slow Annealing

\begin{tabular}{|lcccccc|}
\hline $\begin{array}{l}\text { Selection: Mutagenic } \\
\text { (Molar Ratio) }\end{array}$ & $\begin{array}{c}1: 1 \\
\text { (slow) }\end{array}$ & $\begin{array}{c}1: 5 \\
\text { (slow) }\end{array}$ & $\begin{array}{c}1: 10 \\
\text { (slow) }\end{array}$ & $\begin{array}{c}1: 1 \\
\text { (quick) }\end{array}$ & $\begin{array}{c}1: 5 \\
\text { (quick) }\end{array}$ & $\begin{array}{c}1: 10 \\
\text { (quick) }\end{array}$ \\
\hline $\begin{array}{l}\text { Desired Mutants } \\
\begin{array}{l}\text { Mutants from } \\
\text { Selection-Primer Only }\end{array}\end{array}$ & $<0 \%$ & $<10 \%$ & $<10 \%$ & $<10 \%$ & $60 \%$ & $<10 \%$ \\
\hline
\end{tabular}

sulted from the annealing of only the selection primer. To overcome this problem, we improved the method described by Deng and Nickoloff (2) by optimizing the molar ratio of mutagenic primer to selection primer. The improved procedure described below greatly increased the efficiencies of inserting a 34-bp sequence in front of the insulin response sequence (IRS) of fatty acid synthase (FAS) promoter in the 5.0-kbp parental plasmid p67-LUC.

The mutagenic primer (5'-TGCATGCCTGCAGGTCGACCCCAGTGTCCTCAGTGCAGTTCCCAGTGTGACCAAGCCCATGTGGCGTGGCCGCGC-3') was designed as a 75mer, which contains a 22- and 20-base exact match to the parental plasmid sequence at its $5^{\prime}$ and $3^{\prime}$ ends, respectively, and incorporates the 34-base insertion (underlined) in the middle of the

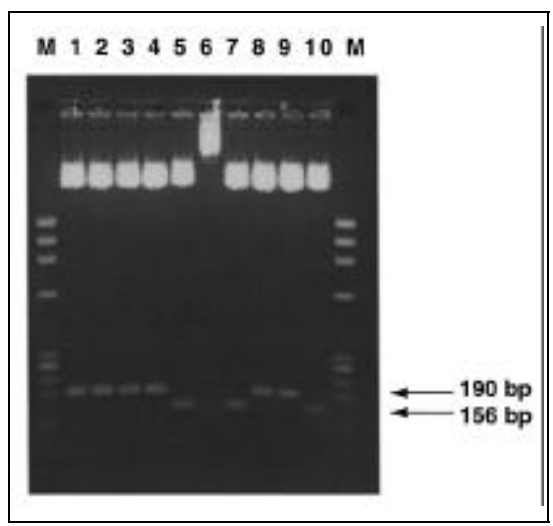

Figure 1. SalI digestion of plasmid DNA from 10 colonies randomly picked from the second transformation. Plasmid DNA was prepared with the alkaline lysis method and digested with $5 \mathrm{U}$ of SalI and applied onto a $2 \%$ agarose gel running in $1 \times \mathrm{TBE}$ and stained with ethidium bromide. Lane M is the $\phi \mathrm{X} 174$ HaeIII marker; and lanes $1-10$ are the DNA samples from the 10 colonies. The 190-bp insert indicates the desired mutants with both the mutagenic and selection primers annealed. The 156-bp insert indicates the mutants from annealing of only the selection primer. Plasmid DNA in lane 6 was not digestable by SalI with reasons not determined. sequence. The selection primer (5'GCTGCAGGAATTCGATGTCGACCTTGGCATTCCGGTAC-5') was designed from the polycloning-site region of the parental plasmid to mutate the unique HindIII site into a SalI site (underlined). Both primers were purified by reverse-phase cartridges (PE Applied Biosystems, Foster City, CA, USA) and phosphorylated with T4 polynucleotide kinase (Amersham, Arlington Heights, IL, USA) at standard conditions (7). Then the following steps were performed.

Step 1. For DNA synthesis, a $20-\mu \mathrm{L}$ annealing reaction containing $1 \times$ annealing buffer $(20 \mathrm{mM}$ Tris- $\mathrm{HCl}, \mathrm{pH}$ 7.5, $\left.10 \mathrm{mM} \mathrm{MgCl}_{2}, 50 \mathrm{mM} \mathrm{NaCl}\right), 1 \mu \mathrm{g}$ of parental plasmid p67-LUC, 10 pmol of selection primer and 10,50 or 100

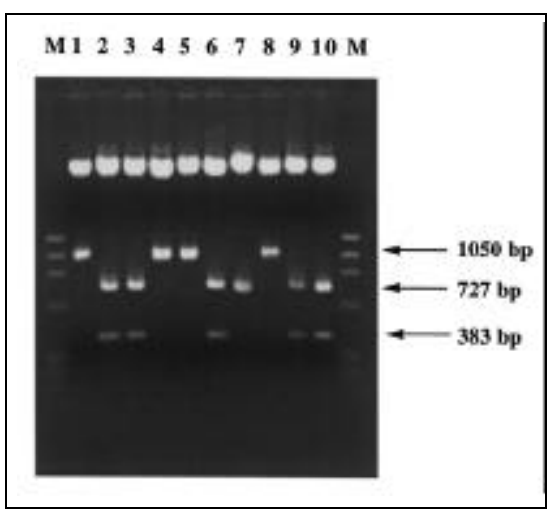

Figure 2. Digestion of plasmid DNA in a deletion mutation experiment with 1:5 molar ratio of selection:mutagenic primers and quick annealing. Selection and mutagenic primers were designed to delete a 60-bp sequence, which contains an $\mathrm{XhoI}$ site, of the mouse upstream stimulatory factor 2 (USF2) cDNA sequence cloned into vector pCDNA3. When digested with EcoRI and $\mathrm{XhoI}$, the parental plasmid yielded two bands

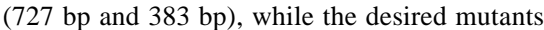
yielded only one band (1050 bp) because of the loss of the internal XhoI site. Lane M is the $\phi X 174$ HaeIII marker; and lanes 1-10 are the DNA samples from 100 colonies randomly picked. Reasons for the loss of the 383-bp band in lane 7 were not determined. The mutagenesis efficiency was calculated as $40 \%$. 


\section{Benchmarks}

pmol of mutagenic primer (resulting in a $1: 1,1: 5$ or $1: 10$ molar ratio of selection:mutagenic primers) was heated in boiling water for $3 \mathrm{~min}$ and either incubated at room temperature for $10 \mathrm{~min}$ as a slow annealing step or immediately chilled on an ice-water bath for $5 \mathrm{~min}$ as a quick annealing step. In the original method (2), a 1:1 primer ratio and a 100:1 primer:template ratio were used, and quick annealing was shown to be more effective than slow annealing. Here we used a 33:1 selection primer:template ratio and 33:1, 166:1 and 333:1 mutagenic primer:template ratios. Then, $6 \mu \mathrm{L}$ of $5 \times$ synthesis buffer $(50$ $\mathrm{mM}$ Tris-HCl, $\mathrm{pH}$ 7.5, $2.5 \mathrm{mM}$ dNTP, 5 $\mathrm{mM}$ ATP, $10 \mathrm{mM}$ dithiothreitol), $1 \mu \mathrm{L}$ of T4 DNA Polymerase (3 U/ $\mu \mathrm{L}$; New England Biolabs, Beverly, MA, USA), $0.5 \mu \mathrm{L}$ of T4 DNA ligase $(2000 \mathrm{U} / \mu \mathrm{L}$; New England Biolabs) and $2.5 \mu \mathrm{L}$ of $\mathrm{dH}_{2} \mathrm{O}$ were added. The mixture was incubated at $37^{\circ} \mathrm{C}$ for $3 \mathrm{~h}$ followed by heat-inactivation at $70^{\circ} \mathrm{C}$ for $5 \mathrm{~min}$.

Step 2. Newly synthesized plasmid was selected by digesting the mixture from step 1 with $20 \mathrm{U}$ of HindIII (New England Biolabs) at $37^{\circ} \mathrm{C}$ for $3 \mathrm{~h}$. And one half of the digestion was used to transform BMH 71-18 MutS E. coli competent cells. Transformed E. coli cells were grown in $5 \mathrm{~mL}$ of $\mathrm{LB}+$ ampicillin $(100 \mu \mathrm{g} / \mathrm{mL})$ at $37^{\circ} \mathrm{C}$ overnight.

Step 3. As a second selection step, 1 $\mu \mathrm{g}$ of the plasmid DNA, prepared by Wizard $^{\mathrm{TM}}$ Minipreps DNA Purification System (Promega, Madison, WI, USA) from cultures of step 2 were digested with $20 \mathrm{U}$ of $\mathrm{HindIII}$ at $37^{\circ} \mathrm{C}$ for $3 \mathrm{~h}$. Competent E. coli JM109 cells were then transformed with the digested plasmid DNA and plated on LB + Amp $(100 \mu \mathrm{g} / \mathrm{mL})$. Plasmid DNA was prepared from the colonies for digestion with SalI to assay for the new SalI site and for the insertion of the 34-bp DNA introduced by the mutagenic primer.

Since there is a SalI site on the parental plasmid upstream of the 34-bp insertion and an additional SalI site was introduced by the selection primer, SalI digestion of the desired mutants will result in an insert of $190 \mathrm{bp}$, while the mutants from annealing of only the selection primer will give an insert of 156 bp. Thus the size of the insert allows the discrimination between the two types of mutants. As shown in Figure 1, of the
10 colonies randomly picked from the plate of 1:5 (selection:mutagenic primer) molar ratio and the quick annealing in step 1, $6(60 \%)$ contained the 190-bp insert and $3(30 \%)$ contained the 156-bp insert. The identities of these clones were also confirmed by DNA sequencing of two representatives. Percentages of the desired mutants and the mutants from the selection primer only under other reaction conditions, including slow annealing as well as using 1:1 and 1:10 (selection:mutagenic primer) molar ratios, were summarized in Table 1 , which demonstrates that, under the described experimental conditions, the 1:5 molar ratio of selection:mutagenic primers, in combination with the quick annealing, gave the best efficiency at a level comparable to the previously reported methods (2) for generating one or a few base pair substitutions and small deletions/insertsions. We have also found that adjusting the molar ratio of selection to mutagenic primers can improve the mutagenesis efficiency for creating deletions. In several cases, using the 1:5 molar ratio of selection: mutagenic primers resulted in a significantly higher efficiency to generate deletions (Figure 2) when the efficiency of using the 1:1 molar ratio is less than 5\% (data not shown). In summary, optimizing the molar ratio of selection to mutagenic primers and using a quick annealing step in the site-directed mutagenesis procedure can be readily adapted to overcome the problems of high background and low efficiency, particularly associated with the generation of large insertions.

\section{REFERENCES}

1.Carter, P. 1987. Improved oligonucleotide-directed mutagenesis using M13 vectors. Methods Enzymol. 154:382-403.

2.Deng, W.P. and J.A. Nickoloff. 1992. Site-directed mutagenesis of virtually any plasmid by eliminating a unique site. Anal. Biochem. 200:81-88.

3.Hemsley, A., N. Arnheim, M.D. Toney, G. Cortopassi and D.J. Galas. 1989. A simple method for site-directed mutagenesis using the polymerase chain reaction. Nucleic Acids Res. 17:6545-6551.

4.Hughes, M.J.G. and D.W. Andrews. 1996. Creation of deletion, insertion and substitution mutations using a single pair of primers and PCR. BioTechniques 20:188-196.

5.Kunkel, T.A. 1985. Rapid and efficient sitespecific mutagenesis without phenotypic selec- tion. Proc. Natl. Acad. Sci. USA 82:488-492.

6.Lewis, M.K. and D.V. Thompson. 1990. Efficient site-directed in vitro mutagenesis using ampicillin selection. Nucleic Acids Res. 18:3439-3443.

7.Sambrook. J., E.F. Fritsch and T. Maniatis. 1989. Molecular Cloning: A Laboratory Manual, 2nd ed. Cold Spring Harbor Laboratory Press, Cold Spring Harbor, NY.

8.Stemmer, W.P.C. and S.K. Morris. 1992. Enzymatic inverse PCR: a restriction site independent, single-fragment method for highefficiency, site-directed mutagenesis. BioTechniques 13:214-220.

9.Tomic, M., I. Sunjevaric, E.S. Savtchenko and M. Blumenberg. 1990. A rapid and simple method for introducing specific mutations into any position of DNA leaving all other positions unaltered. Nucleic Acids Res. 18:1656.

This research was supported in part by Grant DK-36264 from the National Institutes of Health to H.S.S. Address correspondence to Hei Sook Sul, 220 Morgan Hall, Department of Nutritional Science, University of California, Berkeley, CA 94720, USA. Internet: hsul@nature.berkeley.edu

Received 5 April 1996; accepted 28 June 1996.

Dong Wang and Hei Sook Sul University of California Berkeley, CA, USA 